\title{
Nonsuicidal Self-Injury in Adolescents
}

\author{
Paul L. Plener, Michael Kaess, Christian Schmahl, Stefan Pollak, Jörg M. Fegert, Rebecca C. Brown
}

\begin{abstract}
Summary
Background: $25-35 \%$ of adolescents in random samples drawn from German schools have been found to have manifested at least one episode of nonsuicidal self-injury (NSSI). The prevalence in samples from child and adolescent psychiatric clinics is approximately $50 \%$. NSSI can arise as a symptom in the setting of various types of mental illness.
\end{abstract}

Methods: This review is based on a selective literature search carried out in the PubMed, PsyclNFO, and Cochrane Library databases, with special consideration of regional study samples.

Results: NSSI is usually resorted to as a dysfunctional coping strategy for emotional regulation. The main risk factors for NSSI include bullying, accompanying mental illnesses, and a history of abuse and neglect in childhood. Neurobiological studies have shown abnormal stress processing in persons with NSSI and an elevated pain threshold in persons with repetitive NSSI. Psychotherapeutic interventions of various kinds lessen the frequency of NSSI; to date, no particular type of psychotherapy has been found to be clearly superior to the others. Randomized controlled trials have revealed small to moderate effects from dialectic-behavioral therapy and mentalization-based therapy in adolescent patients. No psychoactive drug has yet been found to possess specific efficacy against NSSI in adolescents.

Conclusion: The first ever German-language clinical guidelines for the treatment of NSSI have now been issued. Psychotherapy is the treatment of first choice. More research is needed so that subgroups with different disease courses can be more clearly defined.

\section{Cite this as:}

Plener PL, Kaess M, Schmahl C, Pollak S, Fegert JM, Brown RC:

Nonsuicidal self-injury in adolescents. Dtsch Arztebl Int 2018; 115: 23-30.

DOI: 10.3238/arztebl.2018.0023

Department of Child and Adolescent Psychiatry and Psychotherapy, Ulm University Hospital: Prof. Dr. med. Plener, MHBA, Prof. Dr. med. Fegert, Dr. phil. Brown

University Hospital of Child and Adolescent Psychiatry and Psychotherapy, University of Bern, Switzerland: Prof. Dr. med. Kaess

Department of Child and Adolescent Psychiatry and Psychotherapy, Heidelberg University Hospital: Prof. Dr. med. Kaess

Department of Psychosomatics and Psychotherapy, Central Institute of Mental Health, Medical Faculty Mannheim/Heidelberg University, Mannheim: Prof. Dr. med. Schmahl

Institute of Forensic Medicine at University Medical Center Freiburg: Prof. Dr. med. Pollak
1 ith a lifetime prevalence of $25-35 \%$ of at least one incident of nonsuicidal self-injury in adolescents, Germany is one of the countries with the highest rates in Europe $(1,2)$. For this reason, this topic is of great relevance to physicians in various specialties. In recent years, three guidelines and a Cochrane review have focused on the clinical management of self-harming behaviors in the wider sense (3-6). In the following review article, the authors present the results of a review of the current literature and discuss guideline-conform treatment.

\section{Definition}

Nonsuicidal self-injury (NSSI) is defined as a direct, repetitive, socially unacceptable injury to body tissues, without suicidal intent (7). This includes cutting, scratching, or burning the body's surface as well as hitting against objects, resulting in direct injury to skin or bones. In the International Statistical Classification of Diseases and Related Health Problems (ICD-10), NSSI exists only at the level of a symptom and is not defined as an independent disease entity. NSSI occurs in the context of various mental disorders, but also without accompanying psychopathology (8). Box 1 includes details of the history and definition of NSSI.

NSSI is relevant not only in the area of curative medicine. Self-injury also has a role in the setting of faked crimes - for example, in faked sex crimes, abductions, and assaults. Typically, findings will be in marked contrast to the dramatic narrative describing the purported circumstances. As a rule, what is found is a multitude of individual injuries to body regions that are easily accessible to the "victim's" own dominant hand, with particularly sensitive skin areas spared. The covering garment is often untouched. The scratches, cuts, or abrasions are usually characterized by uniformly low intensity, similar appearance, an elongated pattern, grouping, or parallel order (9). The presenting features of self-injuries without a faked crime are very similar (Figure 1).

\section{Methods}

We conducted a selective literature review by searching the databases PubMed, PsycINFO, and the Cochrane Library, using the search terms "adolesc*", "nssi", "self-injur*", and "self-harm*". We included studies reported in German or English and published since 2007. We selected this time period because data from samples of German adolescents are available only from 2007 onwards. 


\section{Embeddedness in cultural history and definitions of nonsuicidal self-injury}

The first scientific article on self-injury was published-in German-in 1846 (e7), but the current scientific debate around nonsuicidal self-injury (NSSI) started in the 1960s, with work on the wrist-cutting syndrome. Self-injury in the setting of cultural or religious rites dates back to antiquity-for example, in the cult of Attis. Even today, self-injury is practiced in the context of religion or certain cults-for example, self-flagellation in the large religions or other froms of self-injury in indigenous peoples maintaining the traditions and life styles of an early culture (e8). Furthermore, an association between self-injury and different forms of body modification are under discussion, and Favazza (e9) reported on self-injury for esthetic reasons in subcultures. The available studies also support the observation that NSSI is more common in some alternative settings, such as the Goth subculture (24, e10). Current debate concerns the relevance of NSSI as a possible independent disease entity. The US classification system Diagnostic and Statistical Manual of Mental Disorders (DSM-5) (e11) suggests in the research criteria for the first time to consider NSSI as an independent entity. To this end, the DSM-5 defines a frequency criterion (on more than five days within the preceding 12 months). German guidelines also consider the occurrence on five or more days within 12 months as repetitive NSSI (3). The deliberations of the International Classification of Diseases (ICD-11) (beta draft) ${ }^{*}$, do not current include any proposal for an independent diagnosis, but they do include a description of NSSI as "intentional self-inflicted injury to the body, most commonly cutting, scraping, burning, biting, or hitting, with the expectation that the injury will lead to only minor physical harm." Especially in the English and Australian regions, the umbrella term "(deliberate) self-harm" (6) is used, which includes all self-harming activities, independently of any suicidal intention.

${ }^{*}$ icd.who.int/dev11//-m/en (last accessed on 16 August 2017)
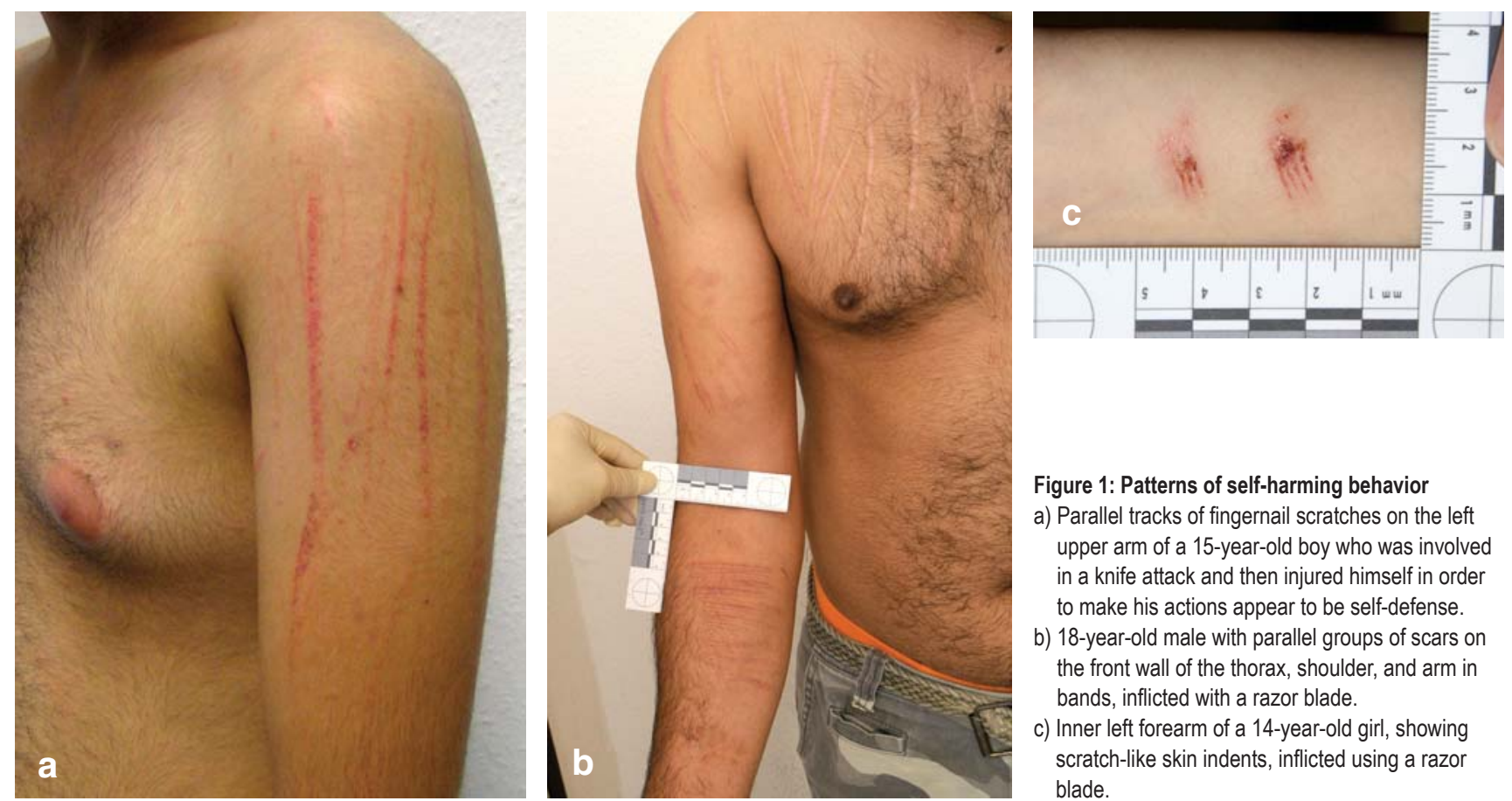

Figure 1: Patterns of self-harming behavior

a) Parallel tracks of fingernail scratches on the left upper arm of a 15 -year-old boy who was involved in a knife attack and then injured himself in order to make his actions appear to be self-defense.

b) 18-year-old male with parallel groups of scars on the front wall of the thorax, shoulder, and arm in bands, inflicted with a razor blade.

c) Inner left forearm of a 14-year-old girl, showing scratch-like skin indents, inflicted using a razor blade. 


\section{Epidemiology}

According to a meta-analysis, the mean lifetime prevalence of at least one occurrence of NSSI in school samples worldwide is $17.2 \%$ (range $8.0-26.3 \%$ ) (10). The rates are much lower in young adults (13.4\%) and older adults (5.5\%) (10). Similar age dependency has been reported for lifetime prevalence rates in Germany: while $25-35 \%$ of adolescents in school samples reported at least one incident of NSSI $(1,2)$, only $3.1 \%$ of the adult general population reported such behavior (11). The situation is similar for repetitive NSSI. In a school sample, $12.25 \%$ of adolescents reported repetitive NSSI ( $\geq 5$ events within their lifespan) (1). By contrast, in a sample taken from the general population in Germany, only $0.3 \%$ reported repetitive NSSI $(\geq 5$ events within the preceding year) (11). Moran et al. reported a longitudinal study (12), which found that NSSI may peak in adolescence; a systematic review of longitudinal studies of NSSI arrived at the same conclusion. The researchers described how the prevalence of NSSI was highest around the $15^{\text {th }}$ and $16^{\text {th }}$ year of life and fell after the $17^{\text {th }}$ year (13). A recent study reported a decrease in repetitive NSSI and suicidal behaviors in adolescents aged 15-17 in Germany at two-year follow-up, whereas high-risk substance misuse increased in this sample, especially in adolescents with frequent NSSI (14). This could be a first indication that in late adolescence, other dysfunctional behaviors will sometimes take over from NSSI.

A meta-analysis showed that NSSI in adolescence and early adulthood more commonly affects young women (odds ratio 1.5) (15), whereas the difference between the sexes is seen more clearly in clinical samples. A difference between the sexes seems to also exist with regard to the methods of NSSI. Young women tend to inflict cuts in more cases $(1,16)$, whereas young men seem to hit themselves more than young women (55.0\% versus $42.4 \%$ ) (16).

\section{Risk factors and functions}

NSSI seems to be associated with many risk factors. Several systematic reviews and meta-analyses identified sometimes overlapping similar factors $(13,17,18)$ (Box 2). Researchers have described the following risk factors in longitudinal studies (13):

- Female sex

- Earlier NSSI

- Earlier suicidal ideation and attempts

- Symptoms of depression

- General psychological stress.

Regarding associations between NSSI and physical maltreatment, abuse, and neglect in childhood (17), a recent study compared different types of maltreatment, abuse, and neglect (19). The study showed that in a pathway model, only emotionally abusive actions were indirectly associated with NSSI via emotional expressiveness (standardized indirect effect $=0.11$; $\mathrm{p}<0.05$ ), although the study also showed significant associations between emotional abuse and sexual abuse or physical maltreatment (19). This seems to
BOX 2

\section{Risk factors for nonsuicidal self-injury ${ }^{{ }^{*}}$}

\section{- Demographic risk factors}

- Female sex*2

- Adolescence*3

- Unemployment ${ }^{*}$

- Living alone ${ }^{*}$

\section{- Familial risk factors}

- Health problems in the family*4

- Mental stress affecting one or both parents ${ }^{* 2}$

- Separated parents*4

- Conflict in parent-child relationship*3

- Mental disorder/symptoms

- Anxiety disorders*3

- Depression and depressive symptoms*2

- Hopelessness ${ }^{\star 2}$

- Aggression, externalizing behavioral abnormalities ${ }^{* 2}$

- Cluster-B personality disorder*3

- Eating disorders*4

- Internalizing behavioral abnormalities ${ }^{* 3}$

- Affect regulation problems ${ }^{{ }_{3}}$

- Substance misuse ${ }^{\star 3}$

- Abuse and physical maltreatment in childhood

- Physical neglect and maltreatment*3

- Emotional neglect and maltreatment ${ }^{* 4}$

- Sexual abuse ${ }^{\star 3}$

- NSSI and suicidal behavior

- Past history of NSSI*3

- Past history of suicidal thoughts and attempts*3

- Experience of NSSI in peers ${ }^{* 3}$

\section{NSSI, nonsuicidal self-injury}

${ }^{*}$ Summarized on the basis of systematic reviews and meta-analyses $(13,17,18)$

${ }^{* 2}$ Mentioned in three articles

*3 Mentioned in two articles

${ }^{*} 4$ Mentioned in one article

complement the findings among German samples regarding associations between NSSI and parental criticism or antipathy towards one's children (20). Parental factors such as the following also played a part and were associated with NSSI in their children (21):

- Alcohol misuse

- Attention deficit/hyperactivity disorder (ADHD)

- Self criticism

- A low degree of compatibility and diligence.

At the level of peer influence, the phenomenon of social contagion was investigated in different settings (22). The authors point out that any so-called social contagion is likely to have a role in the initial contact with NSSI. Maintaining NSSI is often mediated via intrapersonal functions. Furthermore, associations were shown between the occurrence and frequency of NSSI and belonging to alternative youth cultures, for 
example, the Goth subculture (23). NSSI is also a hot topic on the internet (24). Bullying is a crucial social factor of influence in NSSI. Large cross-sectional and longitudinal studies have shown an association between self-reported experiences of bullying in childhood and early adolescence and NSSI in adolescence. In two longitudinal studies, the odds ratio for suicidal behavior and NSSI was 1.6-3.0 (25).

The four-factor model by Nock is often used to explain the motives for NSSI (7). The model identifies intrapersonal and interpersonal functions, and positive or negative amplification mechanisms can have an effect in either of these. Several studies have agreed that NSSI is primarily used to affect aversive emotional states (26).

\section{Psychological comorbidities}

NSSI is not an independent entity in the ICD-10. Other mental disorders are common comorbidities in the context of NSSI (27):

- Affective disorders

- Emotionally unstable personality disorders/borderline personality disorder (BPS)

- Substance misuse and dependence disorders

- Externalizing disorders

- Anxiety disorders

- Post-traumatic stress disorder (PTSD)

- Avoidant personality disorder.

In German-speaking female patients of child and adolescent psychiatrists, the most common comorbid diagnoses described were depression $(79.5 \%)$, social phobia (38.5\%), PTSD (28.2\%), or BPS (20.5\%) (28).

\section{Neurobiology}

Even though neurobiological research into the consequences of NSSI mostly takes recourse to the literature on adults with BPS, in recent years an increasing number of studies have been conducted in adolescents with NSSI. One of the most common foci of research is the (altered) sensation of pain in those who harm themselves. Many adult patients with BPS experience hypoalgesia or analgesia during NSSI and a downregulation of limbic areas subsequent to the pain stimuli (29). However, results reported for adolescents have so far been contradictory (30-32).

Since NSSI is often used to cope with aversive emotional states, neurobiological markers of stress regulation have also been investigated in connection with NSSI. In adolescents with NSSI, cortisol concentrations were raised in the morning (e1) and lowered in the dexamethasone suppression test (e2). The finding of a deviating cortisol response in adolescents with NSSI in a situation of social stress (e3) has been replicated in an independent sample (e4). Interestingly, adolescents with NSSI show a stronger cortisol response to pain stimuli (32).

Adolescents with NSSI seem to primarily process social stressors less well. Genetic analyses - in the sense of a gene-environment interaction-also showed that in carriers of at least one short allele in the serotonin transporter-linked polymorphic region (5-HTTLPR) of the SLC6A4 gene, NSSI is more common when such adolescents encounter severe interpersonal stress $(\mathrm{F}[4,570]=2.65 ; \mathrm{p}<0.05$; partial eta squared $=0.02)(33)$. Because of the singularity of the finding, further studies of gene-environment interactions are highly desirable. Similarly, it was shown that social exclusion in depressed adolescents with NSSI, compared with adolescents without NSSI and health controls, resulted in differences in activation in different cerebral regions (medial prefrontal cortex: k: 26, Z: 3.69, p <0.001; parahippocampus: k: $18, \mathrm{Z}: 3.72, \mathrm{p}<0.001$; supplementary motor area: $\mathrm{k}$ : $13, \mathrm{Z}: 3.45, \mathrm{p}<0.001$ ) (34). Consequently, it is possible that adolescents with NSSI are also subject to particular sensitivity regarding social exclusion from groups. The findings shown here ultimately also highlight the extent of interactions between neurobiological deviations and the risk factors described above, such as bullying, in NSSI. However, it is still not possible to reach a final conclusion on causal associations - or otherwise - because of a lack of longitudinal studies.

\section{Diagnostic evaluation and clinical management}

The diagnosis of NSSI is based primarily on clinical presentation. In addition, several German-language data collection instruments are available (overview in eTable) that have also been validated in samples of adolescents. However, these are mostly used in research. The first step in care provision is a physical investigation. The depth of the wound is examined, as are possible contamination and tetanus vaccination status, and, if necessary, the relevant surgical procedure is initiated (3). Over the subsequent course, a psychopathological evaluation is necessary, including an exploration of acute suicidality. During history taking, the frequency and methods of NSSI and familial and extrafamilial factors influencing NSSI should be elicited, as should be the effects of NSSI on the patient's social or familial environment (Figure 2) (3). A thorough exploration of suicidality is particularly important in adolescents with NSSI (35). Clinically, it should be borne in mind that self-injury and attempted suicide are clearly separate entities with different intentions and functions, although they may often go hand in hand (36) (Box 3).

After acute wounds have been dressed, a psychopathological assessment completed, and acute suicidality ascertained or otherwise, a decision has to be made on how to proceed from there onwards.

In patients subject to acute suicidality, inpatient child and adolescent psychiatric therapy should be initiated. In patients with their first event of NSSI without comorbid psychopathology, the physician should recommend that the patient and their parents or persons in loco parentis should seek out a clinic/ counseling center (3). In patients with repetitive NSSI (Box 1) or comorbid psychopathological findings, subsequent treatment should be administered by someone with specialist professional skills in treating 


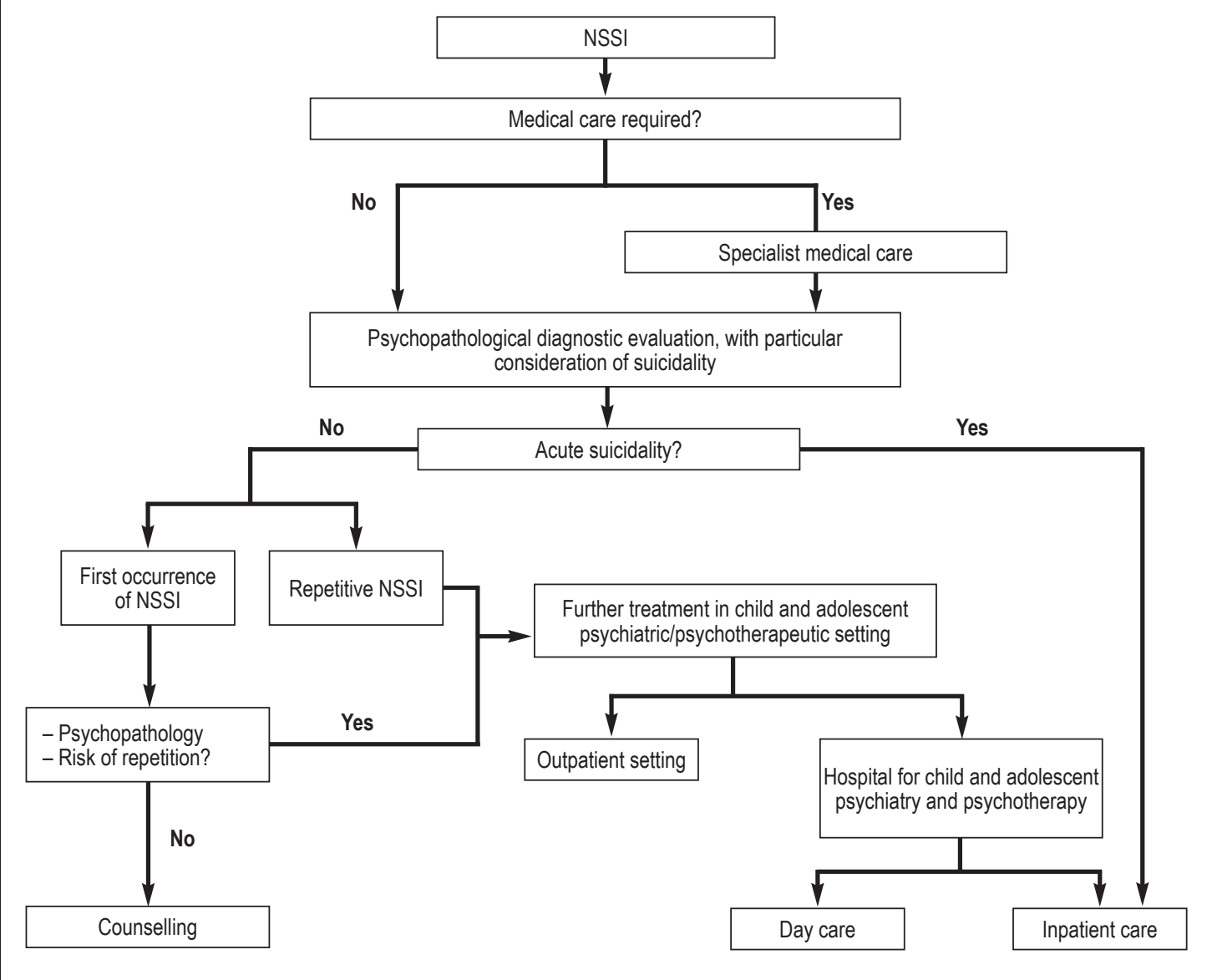

Flow chart of the treatment of nonsuicidal self-injury (simplified), following the guidelines of the Association of Scientific Medical Societies in Germany (AWMF, Arbeitsgemeinschaft der Wissenschaftlichen Medizinischen Fachgesellschaften) (DGKJP, 2015; [3])

DGKJP, German Association for Child and Adolescent Psychiatry, Psychosomatics and Psychotherapy; NSSI, nonsuicidal self-injury

psychological disorders in children and adolescents-for example, physicians specializing in child and adolescent psychiatry and psychotherapy or psychotherapists for children and adolescents. In this setting, making contact quickly is strongly recommended (immediately in acute suicidality; in other cases, clinical experience would advocate a quick referral, within a week, preferably). The degree of suffering that prompted a patient to present to the doctor sometimes increases his/her motivation to make use of the help available.

\section{Therapy}

Even though to date the situation vis-à-vis studies of the effectiveness of psychotherapeutic treatment is still unsatisfactory, a recent meta-analysis generally confirmed the effectiveness of psychotherapeutic methods in treating NSSI in adolescents (37). The therapies that were identified as effective were cognitive behavioral therapy, dialectic behavioral therapy for adolescents (DBT-A), and mentalization-based therapy for adolescents (MBT-A). MBT-A (38) and DBT-A (39) reduced
NSSI in randomized controlled studies. In the MBT-A study with 12 months of follow-up, self-harming behavior decreased in the last three months compared with "treatment as usual." 56\% in the MBT-A group displayed self harming behavior compared with $83 \%$ in the control group $\left(\chi^{2}=5.0 ; \mathrm{p}<0.01\right.$; number needed to treat $[\mathrm{NNT}]$ : 3.66 ; Cohen's $\mathrm{d}=0.73$ ) (38). In the DBT-A study, self-harming behavior decreased after 15 weeks - by $29.8 \%$ in the control group and by $70.7 \%$ in the DBT-A group (delta slope $=-0.92 ; \mathrm{p}<0.05$; $\mathrm{d}_{\text {korr }}=0.32$ ) (39). The effects of the intervention were small to moderate. At 12 month follow-up, the DBT-A group was also superior to the group receiving enhanced usual care (reduction 55.9\% versus 44.9\%; $\mathrm{p}<0.05)$ (e5). A recent Cochrane review of therapy for self-harming behavior reached similar conclusions (6) and explains that the available results for MBT-A and DBT-A justify further evaluation, as does the therapeutic assessment, which is intended to motivate adolescents to undergo further psychotherapy. For the guidelines of the Association of Scientific Medical Societies in Germany (AWMF, Arbeitsgemeinschaft 
BOX 3

\section{Associations and differences between nonsuicidal self-injury and suicidal behavior}

Nonsuicidal self-injury (NSSI) and suicidal behavior are discrete entities, but they can occur in the same person at different time points. A recent comparison of young adults described cutting as the most common method for NSSI, whereas intoxication is the most common method for attempting suicide (e12). Although NSSI is undertaken without suicidal intention, adolescents with NSSI often harbor suicidal thoughts too. They have a notably increased risk for later suicidal ideation (odds ratio 2.95) (e13) and suicide attempts (hazard ratio 2.00) (e14), especially if they undertake long-term repetitive NSSI (e15). In a follow-up study of patients who had presented in hospital with self-harming behavior, the risk for later suicide was increased by a factor of 49 (e16). A recent meta-analysis showed that in the age group of 12-26 year olds, suicides are strongly associated with NSSI and thoughts of NSSI (odds ratio 22.53) (e17). der Wissenschaftlichen Medizinischen Fachgesellschaften) (3), elements were developed that should be heeded when treating adolescents with NSSI (Box 4).

The recently published recommendations from Australia favor a similar approach (4). They name the commonalities of effective programs for reducing NSSI, which include the following interventions:

- Developing the motivation to change

- Support of abstinence

- Support for the environment (family and nonfamily)

- Strengthening positive affect

- A focus on healthy sleep.

Generally, in psychotherapy NSSI should always be treated in the context of other mental disorders if present.

As regards the effectiveness of treatment with psychopharmaceuticals, two systematic reviews concluded that no evidence exists for any specific psychopharmacological measure in NSSI in children and adolescents $(6,40)$. There are very few randomized controlled studies. When adolescents and young adults with borderline personality disorder were included, the substance aripiprazole, among others, reduced the NSSI (e6). Current guidelines mention this finding and see a role for psychopharmacological intervention only for the purpose of shortterm sedation in states of high tension-for example, a great inner pressure to self-injure. Furthermore, the guidelines emphasize that guideline-conform treatment of comorbid mental disorders is indicated (3).

\section{Discussion}

In the past 10 years, numerous studies have provided new information on risk factors, neurobiological associations, and especially therapeutic approaches, with the result that initial recommendations for treatment strategies have been incorporated into clinical guidelines. It was shown that psychotherapeutic measures may reduce NSSI as the method of choice.

However, there is much research still to be done. The question of whether - or if so, which - measures are effective in preventing NSSI remains unanswered. Furthermore, in spite of recent study results regarding social risk factors such as bullying and difficulties in dealing with social stressors, it remains unclear whether-and if so, which - causal association exists between these findings. For this reason, it seems to be highly desirable in this setting to combine in future studies epidemiological and longitudinal research approaches with neurobiological markers. As far as therapeutic research is concerned, it will be necessary to identify early predictors for the course. Accordingly, stepped care services, including online interventions as well as short term programs and longer term psychotherapeutic approaches, could constitute a treatment chain that meets the actual healthcare need. 


\section{Key messages}

- Between a quarter and a third of adolescents in Germany inflict intentional self-injury at least once; a substantial proportion do so repetitively.

- Nonsuicidal self injury (NSSI) accompanies different mental disorders, which have to be considered accordingly when treating NSSI.

- NSSI is often used to regulate aversive emotional states.

- For the diagnostic evaluation of NSSI it is crucial to assess the patient's psychopathological status and acute suicidality.

- The first-line treatment for NSSI is psychotherapy.

\section{Conflict of interest statement}

Prof. Plener is in receipt of royalties relating to the subject matter from Springer and Hogrefe publishers. He has received study funding (third party funding) from Lundbeck and Servier. He has received speaker honoraria from Shire.

Prof. Kaess has received author and coauthor fees from Beltz and Hogrefe publishers.

Prof. Schmahl acts as a consultant for Böhringer Ingelheim.

Prof. Fegert has received travel expenses, speaker honoraria, and sponsorship for events and educational events from Shire. He has conducted clinical trials and acted as a consultant on behalf of Servier and Lundbeck. Prof. Pollack and Dr Brown declare that no conflict of interest exists.

Manuscript received on 2 June 2017, revised version accepted on 17 October 2017.

Translated from the original German by Birte Twisselmann, PhD

\section{References}

1. Brunner R, Kaess M, Parzer $P$, et al.: Life-time prevalence and psychosocial correlates of adolescent direct self-injurious behavior: a comparative study of findings in 11 European countries. J Child Psychol Psychiatry 2014; 55: 337-48

2. Plener PL, Libal G, Keller F, Fegert JM, Muehlenkamp JJ: An international comparison of adolescent non-suicidal self-injury (NSSI) and suicide attempts: Germany and the USA. Psychol Med 2009; 39: 1549-58.

3. Deutsche Gesellschaft für Kinder- und Jugendpsychiatrie, Psychosomatik und Psychotherapie. Leitlinie Nicht-Suizidales Selbstverletzendes Verhalten (NSSV) im Kindes und Jugendalter. www.awmf. org/uploads/tx szleitlinien/028-029l S2k Nicht-suizidalesselbstverletzendes_Verhalten_NSSV_2016-04.pdf (last accessed on 27 May 2017).

4. Carter G, Page A, Large M, et al.: Royal Australian and New Zealand College of Psychiatrists clinical practice guideline for the management of deliberate self-harm. Aust N Z J Psychiatry 2016; 50: 939-1000.

5. National Institute for Health and Care Excellence: Self-harm: quality standard. 2013. www.nice.org.uk/quidance/qs34/resources/self harm-2098606243525 (last accessed 27 May 2017).

6. Hawton K, Witt KG, Taylor Salisbury TL, et al.: Interventions for selfharm in children and adolescents. Cochrane Database Syst Rev 2015; 12: CD012013.

7. Nock MK: Self-injury. Annu Rev Clin Psychol 2010; 6: 339-63.

8. Stanford S, Jones MP: Psychological subtyping finds pathological, impulsive, and 'normal' groups among adolescents who self-harm. J Child Psychol Psychiatry 2009; 50: 807-15.

9. Pollak S: Vortäuschung einer Straftat. In: Brinkmann B, Madea B (eds.): Handbuch gerichtliche Medizin. Berlin, Heidelberg, New York: Springer 2004; 1230-8

10. Swannell SV, Martin GE, Page A, Hasking P, St John NJ: Prevalence of nonsuicidal self-injury in nonclinical samples: systematic review, meta-analysis and meta-regression. Suic Life Threat Behav 2014; 44 : 273-303.

11. Plener PL, Allroggen M, Kapusta ND, Brähler E, Fegert JM, Groschwitz $\mathrm{R}$ : The prevalence of nonsuicidal self-injury (NSSI) in a rep- resentative sample of the German population. BMC Psychiatry 2016; 16: 353.

12. Moran $P$, Coffey $C$, Romaniuk $H$, et al.: The natural history of selfharm from adolescence to young adulthood: a population-based cohort study. Lancet 2012; 379: 236-43.

13. Plener PL, Schuhmacher T, Munz LM, Groschwitz RC: The longitudinal course of non-suicidal self-injury and deliberate self-harm: searching for predictors. A systematic review of the literature. Borderline Personal Disord Emot Dysregul 2015; 2: 2 .

14. Nakar $\mathrm{O}$, Brunner R, Schilling $\mathrm{O}$, et al.: Developmental trajectories of self-injurious behavior, suicidal behavior and substance misuse and their association with adolescent borderline personality pathology. J Affec Dis 2016; 197: 231-8.

15. Bresin K, Schoenleber M: Gender differences in the prevalence of nonsuicidal self-injury: a meta-analysis. Clin Psychol Rev 2015; 38: 55-64.

16. Barrocas AL, Hankin BL, Young JF, Abela JR: Rates of nonsuicidale self-injury in youth: age, sex, and behavioral methods ina community sample. Pediatrics 2012; 130: 39-45.

17. Fliege H, Lee JR, Grimm A, Klapp BF: Risk factors and correlates of deliberate self-harm behavior: a systematic review. J Psychosom Res 2009; 66: 477-93.

18. Fox KR, Franklin JC, Ribeiro JD, Kleiman EM, Bentley KH, Nock MK: Meta-analysis of risk factors for nonsuicidal self-injury. Clin Psychol Rev 2015; 42: 156-67.

19. Thomassin K, Shaffer A, Madden A, Londino DL: Specificity of childhood maltreatment and emotion deficit in nonsuicidal self-injury in an inpatient sample of youth. Psychiatry Res 2016; 244: 103-8.

20. Kaess M, Parzer P, Mattern M, et al.: Adverse childhood experiences and their impact on frequency, severity, and the individual function of nonsuicidal self-injury in youth. Psychiatr Res 2013; 206 265-72.

21. Gromatsky MA, Waszczuk MA, Perlman G, Salis KL, Klein DN, Kotov R: The role of parental psychopathology and personality in adolescent non-suicidal self-injury. J Psychiatr Res 2017; 85: 15-23.

22. Jarvi $S$, Jackson $B$, Swenson $L$, Craford $H$ : The impact of social contagion on non-suicidal self-injury: a review of the literature. Arch Suicide Res 2013; 17: 1-19.

23. Bowes $L$, Carnegie $R$, Pearson $R$, et al.: Risk of depression and self-harm in teenagers identifying with goth subculture: a longitudinal cohort study. Lancet Psychiatry 2015; 2: 793-800.

24. Lewis SP, Seko Y: A double-edged sword: a review of benefits and risks of online nonsuicidal self-injury activities. J Clin Psychol 2016 72: 249-62.

25. Lereya ST, Copeland WE, Costello EJ, Wolke D: Adult mental health consequences of peer bullying and maltreatment in childhood: two cohorts in two countries. Lancet Psychiatry 2015; 2: 524-31.

26. Zetterqvist M, Lundh LG, Dahlstrom O, Svedin CG: Prevalence and function of non-suicidal self-injury (NSSI) in a community sample of adolescents, using suggested DSM-5 criteria for a potential NSSI disorder. J Abnorm Child Psychol 2013; 41: 759-73.

27. Nitkowski D, Petermann F: Selbstverletzendes Verhalten und komorbide psychische Störungen: Ein Überblick. Fortschr Neurol Psychiatr 2011; 79: 9-20.

28. In-Albon T, Ruf C, Schmid M: Proposed diagnostic criteria for the DSM-5 of nonsuicidal self-injury in female adolescents: diagnostic and clinical correlates. Psychiatry J 2013; 159208. 
29. Schmahl C, Baumgärtner U: Pain in borderline personality disorder. Mod Trends Pharmacopsychiatry 2015; 30: 166-75.

30. Ludäscher $P$, von Kalckreuth $C$, Parzer $P$, et al.: Pain perception in female adolescents with borderline personality disorder. Eur Child Adolesc Psychiatry 2015; 24: 351-7.

31. Koenig J, Rinnewitz L, Warth M, et al.: Psychobiological response to pain in female adolescents with nonsuicidal self-injury. J Psychiatry Neurosci 2017; 42: 189-99.

32. Osuch E, Ford K, Wrath A, Bartha R, Neufeld R: Functional MRI of pain application in youth who engaged in repetitive non-suicidal self-injury vs. psychiatric controls. Psychiatry Res 2014; 223: 104-12.

33. Hankin BL, Barrocas AL, Young JF, Haberstick B, Smolen A: 5-HTTLPR $x$ interpersonal stress interaction and nonsuicidal selfinjury in general community sample of youth. Psychiatry Res 2015 225: 609-12.

34. Groschwitz RC, Plener PL, Groen G, Bonenberger M, Abler B: Differential neural processing of social exclusion in adolescents with non-suicidal self-injury: an fMRI study. Psychiatry Res 2016; 255 43-9.

35. Deutsche Gesellschaft für Kinder- und Jugendpsychiatrie, Psychosomatik und Psychotherapie. Leitlinie Suizidalität im Kindesund Jugendalter. www.awmf.org/uploads/tx szleitlinien/ 028-031I_S2k_Suizidalitaet_KiJu_2016-07_01.pdf (last accessed 14 August 2017).

36. Groschwitz RC, Kaess M, Fischer G, et al.: The association of nonsuicidal self-injury and suicidal behavior according to DSM-5 in adolescent psychiatric inpatients. Psychiatry Res 2015; 228: 454-61.
37. Ougrin D, Tranah T, Stahl D, Moran P, Asarnow JR: Therapeutic interventions for suicide attempts and self-harm in adolescents: systematic review and meta-analysis. J Am Acad Child Adolesc Psychiatry 2015; 54: 97-107.

38. Rossouw TI, Fonagy P: Mentalization-based treatment for self-harm in adolescents: a randomized controlled trial. J Am Acad Child Adolesc Psychiatry 2012; 51: 1304-13.

39. Mehlum L, Tørmoen AJ, Ramberg M, et al.: Dialectical behavior therapy for adolescents with repeated suicidal and self-harming behavior: a randomized trial. J Am Acad Child Adolesc Psychiatry 2014; 53: 1082-91.

40. Plener PL, Libal G, Fegert JM, Kölch MG: Psychopharmakologische Behandlung von nicht-suizidalem selbstverletzendem Verhalten (NSSV). Nervenheilkunde 2013; 32: 38-45.

\section{Corresponding author}

Prof. Dr. med. Paul L. Plener, MHBA

Klinik für Kinder- und Jugendpsychiatrie und Psychotherapie

Universitätsklinik Ulm

Steinhövelstraße 5, $89075 \mathrm{UIm}$

paul.plener@uniklinik-ulm.de

\section{Supplementary material}

For eReferences please refer to:

www.aerzteblatt-international.de/ref0318

eTable:

www.aerzteblatt-international.de/18m0023

\section{-O CLINICAL SNAPSHOT}

\section{Multiple Chronic Gouty Tophi}

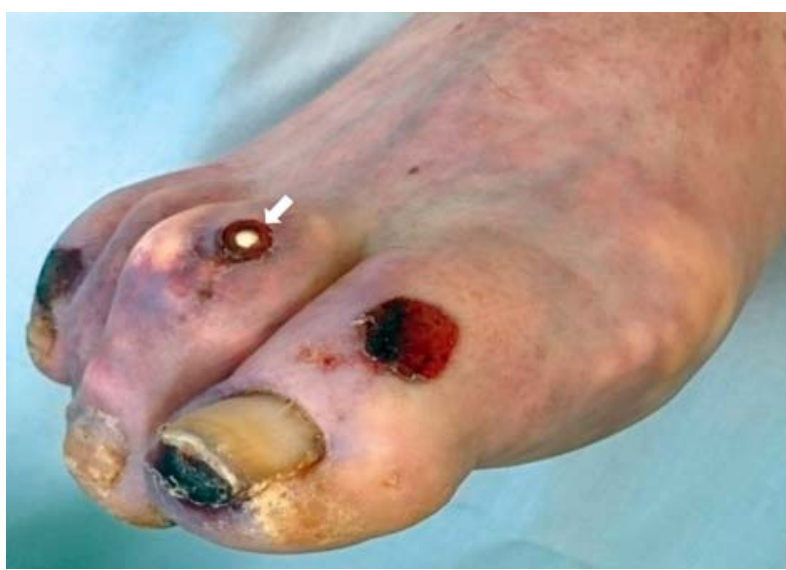

Gouty tophi on the right metatarsophalangeal joint and on the interphalangea joints of the toes of the right foot. The white arrow points to an ulcerated tophus.
A 73-year-old man was admitted to the intensive care unit after suffering a myocardial infarction without ST elevation and undergoing successful cardiopulmonary resuscitation. He had a prior history of coronary heart disease, high-grade ischemic cardiomyopathy, chronic renal failure, and chronic gouty arthritis with multiple gouty tophi. $\mathrm{He}$ had also had hyperuricemia for many years, with uric acid concentrations of up to $9.8 \mathrm{mg} / \mathrm{dl}$. Initial treatment with febuxostat $80 \mathrm{mg}$ bid had failed to lower the uric acid level adequately and was switched to allopurinol $300 \mathrm{mg}$ po qd. This resulted in normalization of the uric acid level, as documented in the current admission $(4.7 \mathrm{mg} / \mathrm{dl})$. The already formed gouty tophi on the tips and joints of the fingers and toes nevertheless persisted. Skin ulcerations caused by gouty tophi were found on the left third toe and the right second toe (Figure).

This case can serve as a reminder that patients with hyperuricemia should be treated with allopurinol as first-line treatment and with febuxostat only as second-line treatment.

Dr. med. Philipp Jud, Klinische Abteilung für Angiologie, Universitätsklinik für Innere Medizin, Medizinische Universität Graz, Österreich

Dr. med. Nicolas Verheyen, Prof. Dr. med. Friedrich Fruhwald, Klinische Abteilung für Kardiologie, Universitätsklinik für Innere Medizin, Medizinische Universität Graz, Osterreich

Conflict of interest statement: The authors state that they have no conflict of interest.

Cite this as: Jud P, Verheyen N, Fruhwald F: Multiple chronic gouty tophi. Dtsch Arztebl Int 2018; 115: 30. DOI: 10.3238/arztebl.2018.0030 Translated from the original German by Ethan Taub, M.D. 
Supplementary material to:

\section{Nonsuicidal Self-Injury in Adolescents}

by Paul L. Plener, Michael Kaess, Christian Schmahl, Stefan Pollak, Jörg M. Fegert, and Rebecca C. Brown

Dtsch Arztebl Int 2018; 115: 23-30. DOI: 10.3238/arztebl.2018.0023

\section{eReferences}

e1. Reichl C, Heyer A, Brunner R, et al.: Hypothalamic-pituitaryadrenal axis, childhood adversity and adolescent nonsuicidal self-injury. Psychoneuroendocrinology 2016; 74: 203-11.

e2. Beauchaine TP, Crowell SE, Hsiao RC: Post-dexamethasone cortisol, self-inflicted injury, and suicidal ideation among depressed adolescent girls. J Abnorm Child Psychol 2015; 43: 619-32.

e3. Kaess M, Hille M, Parzer P, Maser-Gluth C, Resch F, Brunner R: Alterations in the neuroendocrinological stress response to acute psychosocial stress in adolescents engaging in nonsuicidal selfinjury. Psychoneuroendocrinology 2012; 37: 157-61.

e4. Plener PL, Zohsel K, Hohm E, et al.: Lower cortisol level in response to a psychosocial stressor in young females with selfharm. Psychoneuroendocrinology 2017; 76: 84-7.

e5. Mehlum L, Ramberg M, Tørmoen AJ, et al.: Dialectical behavior therapy compared with enhanced usual care for adolescents with repeated suicidal and self-harming behavior: outcomes over a one-year follow-up. J Am Acad Child Adolesc Psychiatry 2016; 55: 295-300.

e6. Nickel MK, Muehlbacher M, Nickel C, et al.: Aripiprazole in the treatment of patients with borderline personality disorder: a double-blind, placebo-controlled study. Am J Psychiatry 2006; 163: 833-8.

e7. Bergmann GH: Ein Fall von religiöser Monomanie. Allgemeine Z Psychiatrie 1846; 3: 365-80.

e8. Favazza AR: The coming of age of self-mutilation. J Nerv Ment Dis 1998; 186: 259-68.

e9. Favazza AR: Bodies under siege. $2^{\text {nd }}$ edition. Baltimore, London: John Hopkins University Press 1992 e10. Young R, Sproeber N, Groschwitz RC, Preiss M, Plener PL: Why alternative teenagers self-harm: exploring the link between nonsuicidal self-injury, attempted suicide and adolescent identity. BMC Psychiatry 2014; 14: 137.

e11. American Psychiatric Association: Diagnostic and statistical manual of mental disorders, $5^{\text {th }}$ edition (DSM-5). American Psychiatric Association 2013.

e12. Brausch AM, Williams AG, Cox EM: Examining intent to die and methods for nonsuicidal self-injury and suicide attempts. Suicide Life Threat Behav 2016; 46: 737-44.

e13. Coppersmith DDL, Nada-Raja S, Beautrais AL: Non-suicidal selfinjury and suicide attempts in a New Zealand birth cohort. J Affect Disord 2017; 221: 89-96.

e14. Chesin MS, Galfavy H, Sonmez CC, et al.: Nonsuicidal self-injury is predictive of suicide attempts among individuals with mood disorders. Suicide Life Threat Behav 2017; doi: 10.1111/sltb.12331.

e15. Koenig J, Brunner R, Fischer G, et al.: Prospective risk for suicidal thoughts and behaviour in adolescents with onset, maintenance or cessation of direct self-injurious behaviour. Eur Child Adolesc Psychiatry 2017; 26: 345-54.

e16. Hawton K, Bergen H, Cooper J, et al.: Suicide following self-harm: findings from the multicentre study of self-harm in England, 2000-2012. J Affect Dis 2015; 175: 147-51.

e17. Castellví P, Lucas Romero E, Miranda-Mendizábal A, et al.: Longitudinal association between self-injurious thoughts and behaviors and suicidal behavior in adolescents and young adults: a systematic review with meta-analysis. J Affect Disord 2017; 215: $37-48$. 


\section{eTABLE}

\section{Standardized German-language data collection instruments}

\begin{tabular}{|c|c|}
\hline Questionnaire instruments & Description \\
\hline Deliberate Self-Harm Inventory (DSHI) & $\begin{array}{l}\text { - Short screening instrument } \\
\text { - Captures several forms of NSSI } \\
\text { - Widely used internationally } \\
\text { - } 17 \text { items }\end{array}$ \\
\hline Self-Harm Inventory (SHI) & $\begin{array}{l}\text { - Captures several, including indirect, forms } \\
\text { of NSSI } \\
\text { - } 22 \text { items }\end{array}$ \\
\hline $\begin{array}{l}\text { Self-Harm Behavior Questionnaire } \\
\text { (SHBQ) }\end{array}$ & $\begin{array}{l}\text { - Captures NSSI, suicidal thoughts, threat of } \\
\text { suicide, and attempted suicide } \\
\text { - Quick to complete } \\
\text { - } 32 \text { items }\end{array}$ \\
\hline $\begin{array}{l}\text { Functional Assessment of } \\
\text { Self-Mutilation (FASM) }\end{array}$ & $\begin{array}{l}\text { - Captures different methods } \\
\text { - Questions about the function of NSSI } \\
\text { - } 42 \text { items }\end{array}$ \\
\hline $\begin{array}{l}\text { Modified Ottawa/Ulm Self-Injury } \\
\text { Inventory (MOUSI) }\end{array}$ & $\begin{array}{l}\text { - Captures functions and methods of NSSI } \\
\text { - Very detailed } \\
\text { - } 36 \text { items, numerous sub-items }\end{array}$ \\
\hline $\begin{array}{l}\text { Self-Injurious Thoughts and } \\
\text { Behaviors Interview (SITBI) }\end{array}$ & $\begin{array}{l}\text { - Standardized interview } \\
\text { - Captures methods, frequencies, and } \\
\text { functions in different areas } \\
\text { - NSSI, thoughts of NSSI, suicidal thoughts, } \\
\text { plans for suicide, suicidal gestures, and } \\
\text { suicide attempts }\end{array}$ \\
\hline
\end{tabular}

NSSI, Nonsuicidal self-injury 